\title{
Impaired psychological recovery in the elderly after the Niigata-Chuetsu Earthquake in Japan:a population-based study Shin-ichi Toyabe*1, Toshiki Shioiri ${ }^{2}$, Hideki Kuwabara ${ }^{2}$, Taroh Endoh ${ }^{2}$, Naohito Tanabe ${ }^{3}$, Toshiyuki Someya ${ }^{2}$ and Kouhei Akazawa ${ }^{1}$
}

\begin{abstract}
Address: ${ }^{1}$ Department of Medical Informatics, Niigata University Medical and Dental Hospital, Asahimachi-Dori 1, Niigata 951-8520, Japan, ${ }^{2}$ Department of Psychiatry, Niigata University Graduate School of Medical and Dental Sciences, Asahimachi-Dori 1, Niigata 951-8510, Japan and ${ }^{3}$ Department of Health Promotion, Niigata University Graduate School of Medical and Dental Sciences, Asahimachi-Dori, Niigata 951-8510, Japan

Email: Shin-ichi Toyabe* - toyabe@med.niigata-u.ac.jp; Toshiki Shioiri - tshioiri@med.niigata-u.ac.jp; Hideki Kuwabara - hkuwa@med.niigatau.ac.jp; Taroh Endoh - toyabe@med.niigata-u.ac.jp; Naohito Tanabe - tanabe@med.niigata-u.ac.jp; Toshiyuki Someya - someya@med.niigatau.ac.jp; Kouhei Akazawa - akazawa@medws1.med.niigata-u.ac.jp

* Corresponding author
\end{abstract}

Published: 14 September 2006

BMC Public Health 2006, 6:230 doi:10.1 I86/147|-2458-6-230
Received: 26 May 2006

Accepted: 14 September 2006

This article is available from: http://www.biomedcentral.com/I47I-2458/6/230

(c) 2006 Toyabe et al; licensee BioMed Central Ltd.

This is an Open Access article distributed under the terms of the Creative Commons Attribution License (http://creativecommons.org/licenses/by/2.0), which permits unrestricted use, distribution, and reproduction in any medium, provided the original work is properly cited.

\begin{abstract}
Background: An earthquake measuring 6.8 on the Richter scale struck the Niigata-Chuetsu region of Japan at 5.56 P.M. on the 23 rd of October, 2004. The earthquake was followed by sustained occurrence of numerous aftershocks, which delayed reconstruction of community lifelines. Even one year after the earthquake, 9,160 people were living in temporary housing. Such a devastating earthquake and life after the earthquake in an unfamiliar environment should cause psychological distress, especially among the elderly.
\end{abstract}

Methods: Psychological distress was measured using the 12-item General Health Questionnaire (GHQ-I2) in 2,083 subjects (69\% response rate) who were living in transient housing five months after the earthquake. GHQ- 12 was scored using the original method, Likert scoring and corrected method. The subjects were asked to assess their psychological status before the earthquake, their psychological status at the most stressful time after the earthquake and their psychological status at five months after the earthquake. Exploratory and confirmatory factor analysis was used to reveal the factor structure of GHQI2. Multiple regression analysis was performed to analyze the relationship between various background factors and GHQ-12 score and its subscale.

Results: GHQ-12 scores were significantly elevated at the most stressful time and they were significantly high even at five months after the earthquake. Factor analysis revealed that a model consisting of two factors (social dysfunction and dysphoria) using corrected GHQ scoring showed a high level of goodness-of-fit. Multiple regression analysis revealed that age of subjects affected GHQ-12 scores. GHQ-12 score as well as its factor 'social dysfunction' scale were increased with increasing age of subjects at five months after the earthquake.

Conclusion: Impaired psychological recovery was observed even at five months after the NiigataChuetsu Earthquake in the elderly. The elderly were more affected by matters relating to coping with daily problems. 


\section{Background}

An earthquake measuring 6.8 on the Richter scale struck the Niigata-Chuetsu region of Japan at 5.56 P.M. on the 23rd of October, 2004. The earthquake was followed by sustained occurrence of numerous aftershocks, one of which measuring 5.0 occurred even on 28th of December, 2004. The earthquake and the following aftershocks left more than 4,500 injured and 120,000 houses completely or partially destroyed. About 100,000 people were displaced from their homes, and some of them moved into temporary housing. Because of the sustained occurrence of aftershocks and delayed reconstruction of community lifelines, 9,160 people who lost their houses were still living in temporary housing even in November 2005, one year after the earthquake. The impact of the devastating earthquake and the following life in an unfamiliar environment should cause psychological distress for people affected by the earthquake [1-5]. Therefore, there was a need to identify the group at high risk for psychological distress after the earthquake [2]. We measured psychological distress using the 12-item General Health Questionnaire (GHQ-12), which is a widely used screening instrument for mental disorders [6,7], among people who were affected by the Niigata-Chuetsu Earthquake and had been living in temporary housing.

Previous studies have shown that the elderly are at high risk for psychological distress as a result of a large disaster $[2,8]$. However, it is not known what aspects of psychological distress are more affected in the elderly than in younger people. We studied the change in GHQ-12 score over time after the earthquake and analyzed the factor structure of the score [6,9-15]. Our results showed that the elderly had greater impairment in recovery from psychological distress, even five months after the earthquake, than did younger subjects. Factor analysis suggested that 'social functioning' was more impaired in the elderly than in younger subjects.

\section{Methods}

Five months after the earthquake, 3,026 subjects who lost houses at the earthquake and had continued to live in temporary housing were asked to reply to questionnaire surveys prepared to measure their psychological distress. A total of 2,083 subjects replied to the questionnaire, a response rate of $69 \%$. Characteristics of the study subjects are outlined in Table 1. Psychological distress was measured using the Japanese version of the 12-item General Health Questionnaire (GHQ-12) [6,7]. To evaluate the changes in psychological distress over time, the subjects were asked to assess their mental state before the earthquake (pre-earthquake), at the time when the subject felt the most stressful after the earthquake (post-earthquake) and at the time of replying to the questionnaire five months after the earthquake (now). The GHQ-12 was scored by the original (0-0-1-1) method (GHQ), corrected scoring (0-1-1-1) by Goodchild (C-GHQ) [16] and Likert (0-1-2-3) scoring [15].

To study factor structure of GHQ-12, exploratory factor analysis was performed [3,6,9-15,17-27]. We used the Promax rotation method because there might be inter-factor correlations $[15,26,28]$. Factors with eigenvalue more than 1.0 were accepted. Internal consistency of a series of items belonging to each factor was evaluated using Cronbach's alpha score [29]. If Cronbach's alpha score of a factor was more than 0.7 , we considered internal consistency of the factor to be satisfactory. In that case, we calculated lower scale points for each factor by averaging scales of all items belonging to the factor. Confirmatory factor analysis was conducted using AMOS 5 (SPSS Japan Inc., Tokyo Japan) to test the fits of models derived from the results of exploratory factor analysis [30]. Since AMOS does not provide tetrachoric correlations, we used binary data as continuous data in spite of problems over handling binary data in factor analysis $[31,32]$. Goodness-of-fit of the models was tested by using F0 (estimated population discrepancy), root mean square error of approximation (RMSEA) and ECVI (expected cross-validation index) [33].

Multiple regression analysis was conducted to evaluate the impact of subjects' background on the GHQ-12 scores. Independent variables used in the analysis are shown in Table 1. Categorical variables and ordered variables were converted to dummy variables. Analysis of variance

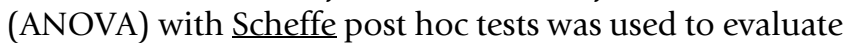
differences over time in the GHQ-12 scores as well as lower scale points of the identified factors. In all tests, a p value less than 0.05 was considered as statistically significant. Analysis other than confirmatory factor analysis was performed using SPSS 14.0J.

This study was approved by the Ethics Committee of Niigata Graduate School of Medical and Dental Sciences. Informed written consent was obtained from all subjects.

\section{Results}

GHQ-12 scored by the three scoring methods was significantly elevated when the subjects felt the most stressful compared to the scores before the earthquake. Although the scores had decreased five months after the earthquake, they were still higher than the scores before the earthquake (Fig. 1).

Exploratory factor analyses revealed that two factors were derived from GHQ-12 scores of three points of time (Table 2). Each of the two factors consisted of the same items regardless of the scoring method and timing of assessment. Factor I consisted of items 1, 3, 4, 7 and 8, and 
Table I: Characteristics of the subjects $(n=2,083)$

\begin{tabular}{|c|c|c|c|}
\hline & & $\mathrm{N}$ & $\%$ \\
\hline \multirow[t]{2}{*}{ Gender } & Male & 1,137 & 54.6 \\
\hline & Female & 927 & 44.5 \\
\hline \multirow[t]{6}{*}{ Age (years) } & $\leq 29$ & 59 & 2.8 \\
\hline & $30-39$ & 184 & 8.8 \\
\hline & $40-49$ & 333 & 16.0 \\
\hline & $50-64$ & 802 & 38.5 \\
\hline & $65-79$ & 623 & 29.9 \\
\hline & $\geq 80$ & 66 & 3.2 \\
\hline \multicolumn{4}{|c|}{ Place of residence when the earthquake occurred } \\
\hline & Nagaoka City & 727 & 34.9 \\
\hline & Ojiya City & 442 & 21.2 \\
\hline & Mitsuke City & $17 \mid$ & 8.2 \\
\hline & Tohkamachi City & 248 & 11.9 \\
\hline & Kawaguchi Town & 146 & 7.0 \\
\hline & Koshiji Town & 108 & 5.2 \\
\hline & Yamakoshi Village & 216 & 10.4 \\
\hline \multirow[t]{9}{*}{ Employment } & Farmer & 236 & 11.3 \\
\hline & Executive of business firm & 128 & 6.1 \\
\hline & Office worker & 461 & 22.1 \\
\hline & Government official & 54 & 2.6 \\
\hline & Part-time worker & 167 & 8.0 \\
\hline & Housewife & 303 & 14.5 \\
\hline & Student & 5 & 0.2 \\
\hline & None & 201 & 9.6 \\
\hline & Pensioner & 295 & 14.2 \\
\hline \multicolumn{4}{|c|}{ Location when the earthquake occurred } \\
\hline & At home & 1,426 & 68.5 \\
\hline & At home of friends & 30 & 1.4 \\
\hline & At office & 132 & 6.3 \\
\hline & In Car & 169 & 8.1 \\
\hline & In bus or train & 8 & 0.4 \\
\hline & In public facilities & 29 & $\mathrm{I} .4$ \\
\hline & In other buildings & 71 & 3.4 \\
\hline & Outdoors & 78 & 3.7 \\
\hline \multicolumn{4}{|c|}{ Person by their side when the earthquake occurred } \\
\hline & With someone & 317 & 15.2 \\
\hline & Alone & 1,766 & 84.8 \\
\hline \multicolumn{4}{|l|}{ Family members living together } \\
\hline & None & 847 & 40.7 \\
\hline \multicolumn{4}{|l|}{ Income } \\
\hline & Lost income after earthquake & 21 & 1.0 \\
\hline \multirow[t]{5}{*}{ Severity of house damage } & Completely destroyed & 356 & 17.1 \\
\hline & Almost completely destroyed & 292 & 14.0 \\
\hline & Severely damaged & 621 & 29.8 \\
\hline & Slightly damaged & 787 & 37.8 \\
\hline & None & 14 & 0.7 \\
\hline \multicolumn{4}{|c|}{ Timing of contact with lifeguards after the earthquake } \\
\hline & $\leq \mathrm{l}$ hour & 139 & 6.7 \\
\hline & $1<\leq 3$ hours & 263 & 12.6 \\
\hline & $3<\leq 6$ hours & 187 & 9.0 \\
\hline & $6<\leq 12$ hours & 204 & 9.8 \\
\hline & $>12$ hours & 998 & 47.9 \\
\hline & No contact & 279 & 13.4 \\
\hline \multirow[t]{3}{*}{ Injury caused by the earthquake } & No injury & 1,888 & 90.6 \\
\hline & Mild injury & 191 & 9.2 \\
\hline & Injury requiring hospitalization & 4 & 0.2 \\
\hline \multirow[t]{3}{*}{ Sickness after the earthquake } & No sickness & 1,870 & 89.8 \\
\hline & Mild sickness & 195 & 9.4 \\
\hline & Sickness requiring hospitalization & 18 & 0.9 \\
\hline
\end{tabular}



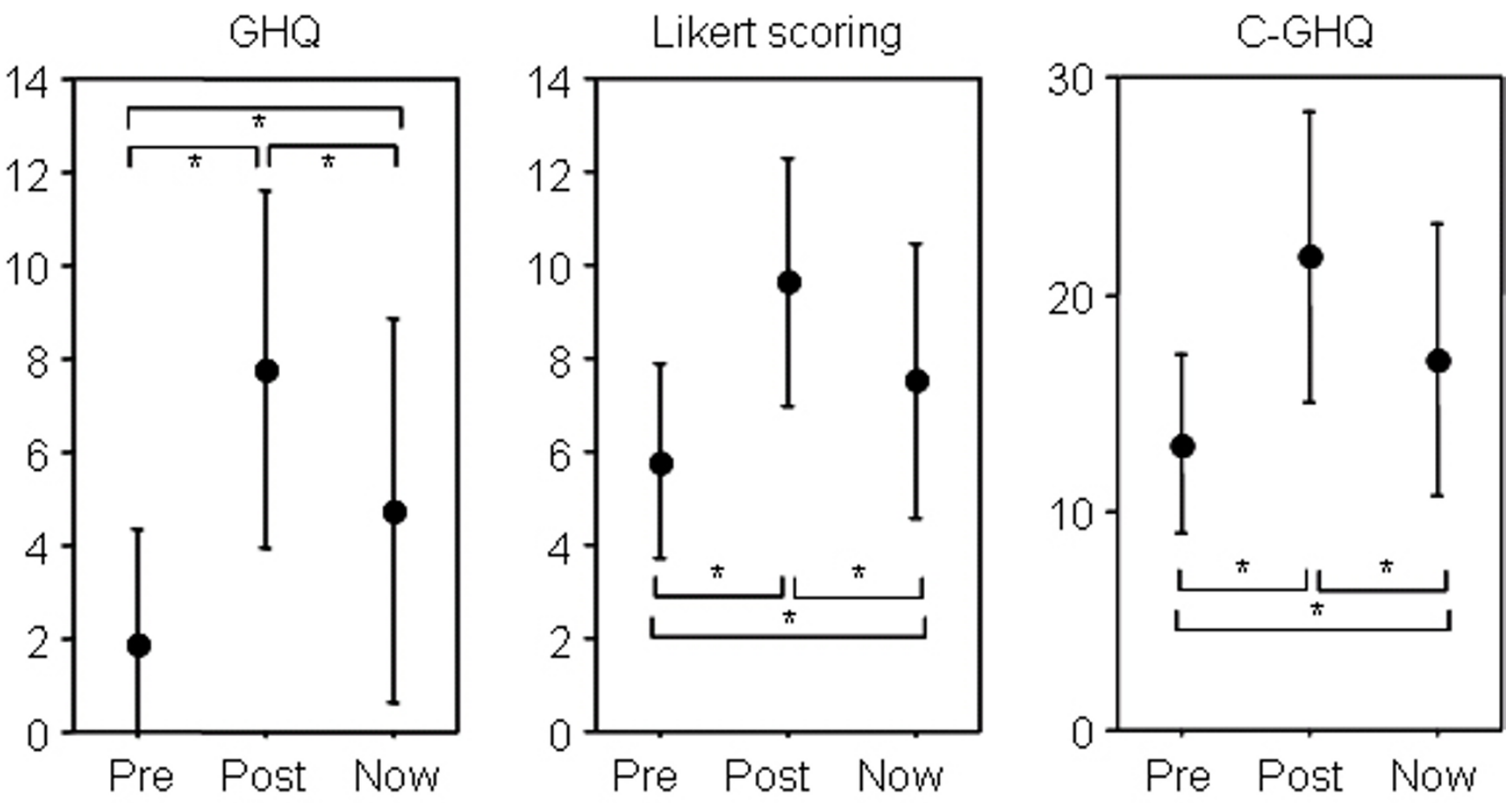

Figure I

Time course of GHQ- 12 scored by three different methods. GHQ- 2 scores were assessed five months after the earthquake, and the subjects were required to assess mental state before the earthquake (Pre), mental state at the most stressful time after the earthquake (Post) and mental state at the time of assessment (Now). Mean and standard deviation val-

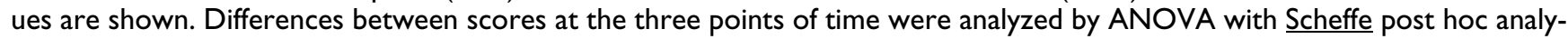
sis. A p-value less than 0.01 is indicated by an asterisk (*).

factor II consisted of items 2, 5, 6, 9, 10 and 11. This twofactor structure was the same as the two-factor model developed by Doi [6]. We defined factor I as 'social dysfunction' related to the ability to cope with everyday problems and factor II as 'dysphoria' related to anxiety and depression according to previous studies [6,9-15]. Item 12 ('feeling reasonably happy') did not belong to either factor I or factor II. There were no or only weak correlations between the factors when C-GHQ scoring was used. On the other hand, comparatively strong correlations were found between the factors when the other scoring methods were used.

Confirmatory factor analysis using the two-factor model showed favorable model fitting in terms of three measures for goodness-of-fit regardless of the difference in the scoring methods (Table 3 ). Although there were no significant differences ( $\alpha=0.1)$ in the three fitting measures between the three scoring methods, the C-GHQ method generally produced the most optimal fitting measures compared with the original GHQ and Likert scoring, except RMSEA evaluated at five months after the earthquake. Therefore, we used the C-GHQ score in the subsequent analyses.
Cronbach's alpha scores for the two factors ranged from 0.85 to 0.91 in C-GHQ scores at the three points of time. Therefore, we considered that the internal consistency of the two factors was sufficient at all three points of time. We calculated the lower scale points for each factor by averaging the scores of all items belonging to the factor.

Next, we analyzed the factor that affects GHQ-12 scores at the three points of time using multiple regression analysis with dummy variables. Table 4 shows regression coefficients of each dependent variable that significantly affect GHQ-12 score. The results of the analysis showed that GHQ-12 scores were associated with various factors, including age of subjects. The results of ANOVA showed that there was a tendency for the GHQ-12 score at five months after the earthquake to increase with increasing age of subjects (Fig. 2). On the other hand, there were no differences between age groups in GHQ-12 score before and after the earthquake. We then analyzed which factor was more affected by age of subjects, considering the results of factor analysis. As shown in Table 4, the results of multiple regression analysis showed that the lower scale point at factor I five months after the earthquake was 
Table 2: Factor loadings

\begin{tabular}{|c|c|c|c|c|c|c|c|}
\hline & \multirow[t]{2}{*}{ GHQ- 12 items } & \multicolumn{2}{|c|}{$\mathrm{GHQ}$} & \multicolumn{2}{|c|}{ Likert } & \multicolumn{2}{|c|}{ C-GHQ } \\
\hline & & $\mathrm{FI}$ & F2 & $\mathrm{FI}$ & $\mathrm{F} 2$ & $\mathrm{FI}$ & $\mathrm{F} 2$ \\
\hline & I. Able to concentrate & 0.68 & - & 0.66 & - & 0.66 & - \\
\hline & 2. Lost much sleep & - & 0.62 & - & 0.65 & - & 0.62 \\
\hline & 3. Playing a useful part & 0.69 & - & 0.71 & - & 0.70 & - \\
\hline & 4. Capable of making decisions & 0.77 & - & 0.81 & - & 0.75 & - \\
\hline & 5. Under stress & - & 0.71 & - & 0.76 & - & 0.76 \\
\hline & 6. Could not overcome difficulties & - & 0.69 & - & 0.71 & - & 0.75 \\
\hline \multirow[t]{13}{*}{ Before earthquake } & 7. Enjoy normal activities & 0.76 & - & 0.72 & - & 0.78 & - \\
\hline & 8. Face up to problems & 0.72 & - & 0.77 & - & 0.74 & - \\
\hline & 9. Feeling unhappy and depressed & - & 0.82 & - & 0.84 & - & 0.81 \\
\hline & 10. Losing confidence & - & 0.72 & - & 0.78 & - & 0.81 \\
\hline & II. Thinking of self as worthless & - & 0.48 & - & 0.52 & - & 0.58 \\
\hline & 12. Feeling reasonably happy & - & - & - & - & - & - \\
\hline & Inter-factor correlation & \multicolumn{2}{|c|}{0.43} & \multicolumn{2}{|c|}{0.43} & \multicolumn{2}{|c|}{0.13} \\
\hline & I. Able to concentrate & 0.76 & - & 0.73 & - & 0.76 & - \\
\hline & 2. Lost much sleep & - & 0.55 & - & 0.63 & - & 0.59 \\
\hline & 3. Playing a useful part & 0.73 & - & 0.79 & - & 0.80 & - \\
\hline & 4. Capable of making decisions & 0.77 & - & 0.81 & - & 0.81 & - \\
\hline & 5. Under stress & - & 0.58 & - & 0.78 & - & 0.79 \\
\hline & 6. Could not overcome difficulties & - & 0.66 & - & 0.73 & - & 0.82 \\
\hline \multirow[t]{13}{*}{ Most stressful time } & 7. Enjoy normal activities & 0.80 & - & 0.69 & - & 0.80 & - \\
\hline & 8. Face up to problems & 0.83 & - & 0.84 & - & 0.85 & - \\
\hline & 9. Feeling unhappy and depressed & - & 0.84 & - & 0.89 & - & 0.85 \\
\hline & 10. Losing confidence & - & 0.78 & - & 0.76 & - & 0.82 \\
\hline & II. Thinking of self as worthless & - & 0.49 & - & 0.48 & - & 0.48 \\
\hline & 12. Feeling reasonably happy & - & - & - & - & - & - \\
\hline & Inter-factor correlation & \multicolumn{2}{|c|}{0.74} & \multicolumn{2}{|c|}{0.71} & \multicolumn{2}{|c|}{0.40} \\
\hline & I. Able to concentrate & 0.77 & - & 0.73 & - & 0.77 & - \\
\hline & 2. Lost much sleep & - & 0.70 & - & 0.72 & - & 0.63 \\
\hline & 3. Playing a useful part & 0.82 & - & 0.79 & - & 0.82 & - \\
\hline & 4. Capable of making decisions & 0.83 & - & 0.81 & - & 0.84 & - \\
\hline & 5. Under stress & - & 0.78 & - & 0.82 & - & 0.76 \\
\hline & 6. Could not overcome difficulties & - & 0.66 & - & 0.77 & - & 0.80 \\
\hline \multirow[t]{7}{*}{ Now } & 7. Enjoy normal activities & 0.73 & - & 0.71 & - & 0.80 & - \\
\hline & 8. Face up to problems & 0.78 & - & 0.77 & - & 0.83 & - \\
\hline & 9. Feeling unhappy and depressed & - & 0.85 & - & 0.91 & - & 0.86 \\
\hline & 10. Losing confidence & - & 0.72 & - & 0.85 & - & 0.86 \\
\hline & II. Thinking of self as worthless & - & 0.40 & - & 0.47 & - & 0.55 \\
\hline & 12. Feeling reasonably happy & - & - & - & - & - & - \\
\hline & Inter-factor correlation & \multicolumn{2}{|c|}{0.73} & \multicolumn{2}{|c|}{0.70} & \multicolumn{2}{|c|}{0.30} \\
\hline
\end{tabular}

Factor analysis was conducted for GHQ-12 scores at three points of time. GHQ- 12 was scored by using the three different methods.

significantly affected by age of subjects, whereas that of factor II was not (Fig. 3). The lower scale points of the two factors before the earthquake showed different change with increasing age of subjects (Fig.3). In the case of GHQ-12 before the earthquake, the lower scale point of factor I increased with increasing age of subjects, but that of factor II decreased.

\section{Discussion}

In the present study, we found that the elderly had greater impairment in recovery from psychological distress than did younger subjects after the Niigata-Chuetsu Earthquake. The level of psychological morbidity assessed using GHQ-12 was lower than that before the earthquake even at five months after the earthquake. At that point of time, the elderly were more affected by matters relating to coping with daily problems, as shown by confirmatory factor analysis of GHQ-12.

Previous studies have suggested that there are some predictors of psychological morbidity after an earthquake $[2,4]$. The elderly $[2,8]$, females [34] and subjects exposed to disruption are at risk for development of psychological distress [2]. Exposure to disruption is estimated by location at the time of the earthquake. Our results of multiple regression analysis suggest that various factors, including the abovementioned risk factors, affect psychological outcome at five months after the earthquake. We found that 
Table 3: Fit measures of models derived from factor analysis

\begin{tabular}{lcccc}
\hline & scoring methods & F0 & RMSEA & ECVI \\
\hline Pre-earthquake & GHQ & 0.138 & 0.058 & 0.207 \\
& Likert & 0.136 & 0.057 & 0.205 \\
Post-earthquake & C-GHQ & 0.098 & 0.048 & 0.167 \\
& GHQ & 0.222 & 0.071 & 0.291 \\
& Likert & 0.225 & 0.072 & 0.294 \\
Now & C-GHQ & 0.196 & 0.066 & 0.266 \\
& GHQ & 0.180 & 0.067 & 0.249 \\
& Likert & 0.180 & 0.071 & 0.249 \\
& C-GHQ & 0.180 & 0.068 & 0.249
\end{tabular}

aging was a risk factor that impaired recovery from psychological distress at five months after the NiigataChuetsu Earthquake. The elderly were more affected by matters relating to coping with daily problems than were younger subjects, as shown by the results of factor analysis.
We found that the two-factor model using C-GHQ scoring was best fitted to scores of the three points of time. Moreover, the impairment of recovery from psychological distress in the elderly was obvious in the factor 'social dysfunction' but was not obvious in the factor 'dysphoria'. GHQ-12 is widely used as a uni-dimensional instrument $[9,11]$, but two or three factors in GHQ-12 have been identified in previous studies $[9,12,14]$. The most common factors that have been identified are a factor for anxiety and depression and a factor for social dysfunction. In general, the factor structure of GHQ-12 has provided quite different results in terms of scoring methods, clinical groups and different cultures [12]. However, the factor structure in the present study was quite stable regardless of the difference in scoring methods. Some researchers have demonstrated that their factor model showed a good fit for C-GHQ scoring compared to that for scoring by other methods $[9,16]$. Our results confirm the results of these studies. Moreover, the weak correlation between the factors suggests that GHQ-12 is a multi-dimensional instrument when applied to the subjects who suffered in the Niigata-Chuetsu Earthquake. Using the factors separately

Table 4: Multiple regression analysis of factors that affected GHQ- 12

\begin{tabular}{|c|c|c|c|c|c|c|c|c|c|}
\hline & \multicolumn{3}{|c|}{ Total } & \multicolumn{3}{|c|}{ Factor I } & \multicolumn{3}{|c|}{ Factor II } \\
\hline & Pre- & Post- & Now & Pre- & Post- & Now & Pre- & Post- & Now \\
\hline Female gender & & 0.11 & 0.05 & & 0.12 & 0.07 & 0.08 & 0.08 & 0.07 \\
\hline Age & & & 0.06 & 0.06 & & 0.11 & & & \\
\hline \multicolumn{10}{|c|}{ Place of residence when the earthquake occurred } \\
\hline Nagaoka City & & & & & & 0.07 & & & \\
\hline Ojiya City & & & -0.14 & & & & & & \\
\hline Mitsuke City & & & & & & & -0.06 & & \\
\hline Kawaguchi Town & 0.07 & & & 0.07 & 0.05 & 0.09 & & & \\
\hline Yamakoshi Village & & & 0.10 & & & 0.14 & & & \\
\hline \multicolumn{10}{|l|}{ Employment } \\
\hline Executive of business firm & & -0.06 & -0.05 & -0.05 & -0.06 & & & & \\
\hline Office worker & & & & & & & & & 0.05 \\
\hline Disemployment & & & & & & & & -0.06 & \\
\hline \multicolumn{10}{|l|}{ Location when the earthquake occurred } \\
\hline At home & & 0.05 & & & 0.06 & & & & \\
\hline In public facilities & & & & & & & 0.05 & & \\
\hline No family members living together & & & & & & 0.04 & & & \\
\hline Lost income after earthquake & & & & & & 0.06 & & & \\
\hline \multicolumn{10}{|l|}{ Severity of house damage } \\
\hline Severely damaged & 0.08 & & & & & 0.10 & & & \\
\hline Almost completely destroyed & & & & 0.10 & & 0.15 & & & \\
\hline \multicolumn{10}{|l|}{ Timing of contact with lifeguards } \\
\hline I to 3 hours after the earthquake & & 0.09 & & & 0.08 & & & & \\
\hline 3 to 6 hours & & 0.12 & & & 0.10 & & & & \\
\hline 6 to 12 hours & & & & & & & & 0.08 & \\
\hline more than 12 hours & & 0.16 & & & 0.15 & & & & \\
\hline No contact & & & & & & & 0.05 & 0.08 & \\
\hline Mild injury caused by the earthquake & & 0.06 & 0.10 & & 0.06 & 0.10 & & & \\
\hline Mild sickness after the earthquake & & 0.07 & 0.09 & & 0.08 & 0.09 & & & \\
\hline Adjusted $\mathrm{R}$ square & 0.01 & 0.08 & 0.12 & 0.02 & 0.07 & 0.14 & 0.02 & 0.03 & \\
\hline
\end{tabular}



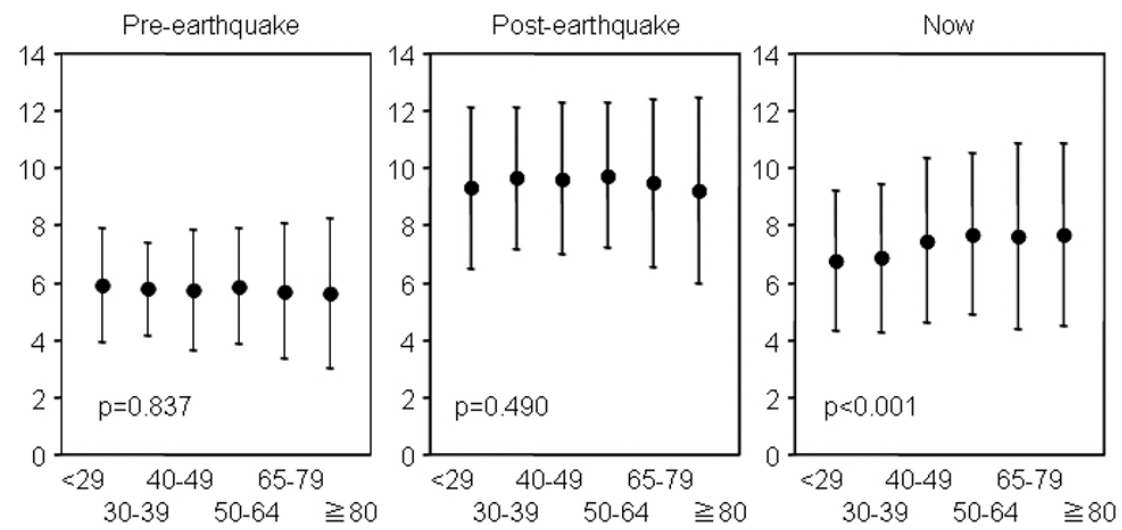

Figure 2

Difference in C-GHQ scores by age. C-GHQ scores before the earthquake (pre-earthquake), at the most stressful time after the earthquake (post-earthquake) and five months after the earthquake (now) are shown as mean and standard deviation values. In each graph, plots from left to right correspond to the six age groups shown in Table I. The effect of age of subjects on the GHQ- 12 scores was analyzed by ANOVA. The $p$ value in each test is shown in the plot.
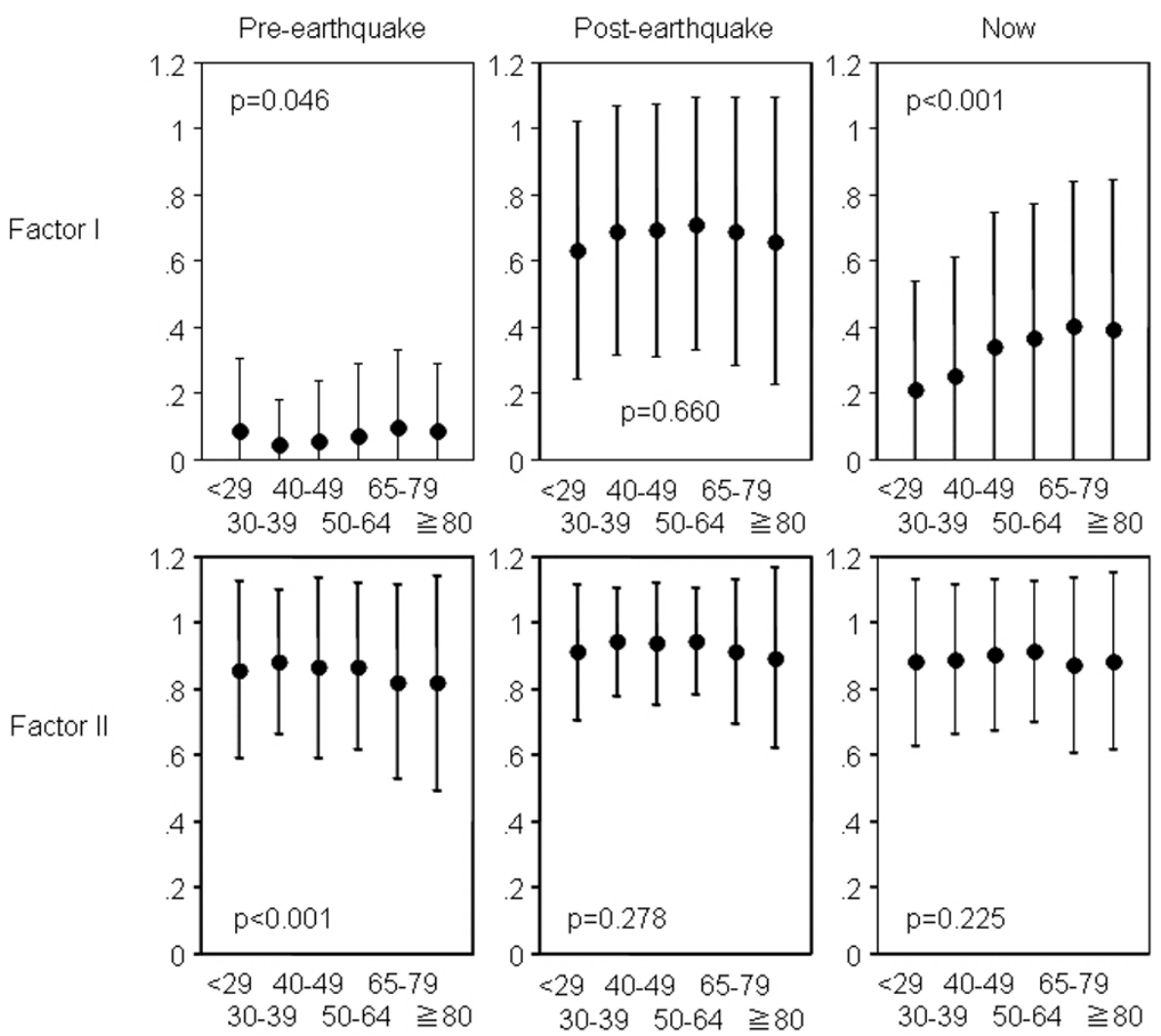

Figure 3

Differences in lower scale points of each factor by age group of subjects. The relationships between subjects' age and factor I or factor II points of pre-earthquake, post earthquake and now are shown as mean and standard deviation values. In each graph, plots from left to right correspond to the six groups of age shown in Table I. Trends of GHQ- 12 scores with increasing age of subjects were analyzed by the ANOVA. The $p$ value in each test is shown in the plot. 
offers a practical advantage in identifying psychological problems in the elderly.

There were some limitations of our study. First, only data from subjects who were affected by the earthquake and continued to live in temporary housing were used for analysis. Data for subjects less affected or unaffected by the earthquake were not included in our study. Second, the pre-earthquake and post-earthquake GHQ-12 scores were assessed five months after the earthquake. The preearthquake and post-earthquake GHQ-12 scores might not be accurate because they were assessed while remembering past events. Self perceptions of well-being before the earthquake are likely to be affected by how individuals are currently feeling. That is why the elderly might underestimate matters relating to pre-earthquake factor II. For the same reason, some post-earthquake items were associated with pre-earthquake GHQ scores in multiple regression analysis. Many studies have suggested that aging influences memories [35, 36, 37]. Nevertheless, it is obvious that the elderly were more affected by matters related to factor I even five months after the earthquake and that special care is needed for the elderly who suffered in the earthquake in order to resolve these problems.

\section{Conclusion}

Impaired psychological recovery was observed even at five months after the Niigata-Chuetsu Earthquake in the elderly. The elderly were more affected by matters relating to coping with daily problems.

\section{Competing interests}

The author(s) declare that they have no competing interests.

\section{Authors' contributions}

ST contributed to concept and design of the article and analysis of data. TS1, HK and TE contributed to acquisition of data. NT contributed to statistical analysis of data. TS2 and AK supervised all aspects of the study and revised the article. All authors read and approved the final manuscript.

\section{Acknowledgements}

We would like to thank Ms. Akane Inaizumi and Ms. Atsuko Sugiyama for preparing the references.

\section{References}

I. Montazeri A, Baradaran H, Omidvari S, Azin SA, Ebadi M, Garmaroudi G, Harirchi AM, Shariati M: Psychological distress among Bam earthquake survivors in Iran: a population-based study. BMC Public Health 2005, 5:4.

2. Carr VJ, Lewin TJ, Webster RA, Kenardy JA: A synthesis of the findings from the Quake Impact Study: a two-year investigation of the psychosocial sequelae of the 1989 Newcastle earthquake. Soc Psychiatry Psychiatr Epidemiol 1997, 32: I23-I36.

3. Carr VJ, Lewin TJ, Kenardy JA, Webster RA, Hazell PL, Carter GL, Williamson M: Psychosocial sequelae of the 1989 Newcastle earthquake: III. Role of vulnerability factors in post-disaster morbidity. Psychol Med 1997, 27:179-190.

4. Carr VJ, Lewin TJ, Webster RA, Kenardy JA, Hazell PL, Carter GL: Psychosocial sequelae of the 1989 Newcastle earthquake: II. Exposure and morbidity profiles during the first 2 years postdisaster. Psychol Med 1997, 27:167-178.

5. Kenardy JA, Webster RA, Lewin TJ, Carr VJ, Hazell PL, Carter GL: Stress debriefing and patterns of recovery following a natural disaster. J Trauma Stress 1996, 9:37-49.

6. Doi Y, Minowa M: Factor structure of the I2-item General Health Questionnaire in the Japanese general adult population. Psychiatry Clin Neurosci 2003, 57:379-383.

7. Goldberg D: The Detection of Psychiatric Illness by Questionnaire: A Technique for the Identification and Assessment of Non-psychotic Psychiatric IIIness. Maudsley Monograph No. 21 London, Oxford University Press; 1972.

8. Webster R, McDonald R, Lewin T, Carr V: Effects of a natural disaster on immigrants and host population. J Nerv Ment Dis 1995, 183:390-397.

9. Martin CR, Newell RJ: The factor structure of the I/2-item General Health Questionnaire in individuals with facial disfigurement. J Psychosom Res 2005, 59:193-199.

10. Lopez-Castedo A, Fernandez L: Psychometric properties of the Spanish version of the 12-item General Health Questionnaire in adolescents. Percept Mot Skills 2005, 100:676-680.

II. Gao F, Luo N, Thumboo J, Fones C, Li SC, Cheung YB: Does the I2item General Health Questionnaire contain multiple factors and do we need them? Health Qual Life Outcomes 2004, 2:63.

12. Campbell A, Walker J, Farrell G: Confirmatory factor analysis of the GHQ-I 2: can I see that again? Aust N Z J Psychiatry 2003, 37:475-483.

13. Daradkeh TK, Ghubash R, el-Rufaie OE: Reliability, validity, and factor structure of the Arabic version of the I2-item General Health Questionnaire. Psychol Rep 200I, 89:85-94.

14. Werneke U, Goldberg DP, Yalcin I, Ustun BT: The stability of the factor structure of the General Health Questionnaire. Psychol Med 2000, 30:823-829.

15. Politi PL, Piccinelli M, Wilkinson G: Reliability, validity and factor structure of the 12-item General Health Questionnaire among young males in Italy. Acta Psychiatr Scand 1994, 90:432-437.

16. Goodchild $M$, Duncan-Jones P: Chronicity and the General Health Questionnaire. Br J Psychiatry 1985, 146:55-6I.

17. Araya R, Dunstan F, Playle R, Thomas H, Palmer S, Lewis G: Perceptions of social capital and the built environment and mental health. Soc Sci Med 2006, 62:3072-83.

18. Wang WC, Cunningham EG: Comparison of alternative estimation methods in confirmatory factor analyses of the General Health Questionnaire. Psychol Rep 2005, 97:3-10.

19. Shevlin M, Adamson G: Alternative factor models and factorial invariance of the GHQ-12: a large sample analysis using confirmatory factor analysis. Psychol Assess 2005, 17:231-236.

20. Lipsanen $T$, Saarijarvi $S$, Lauerma $H$ : Exploring the relations between depression, somatization, dissociation and alexithymia - overlapping or independent constructs? Psychopathology 2004, 37:200-206.

21. Del Piccolo L, Putnam SM, Mazzi MA, Zimmermann C: The biopsychosocial domains and the functions of the medical interview in primary care: construct validity of the Verona Medical Interview Classification System. Patient Educ Couns 2004, 53:47-56.

22. Muller L, Spitz E: Multidimensional assessment of coping: validation of the Brief COPE among French population. Encephale 2003, 29:507-5I8.

23. French DJ, Tait RJ: Measurement invariance in the General Health Questionnaire-12 in young Australian adolescents. Eur Child Adolesc Psychiatry 2004, 13:1-7.

24. Sham PC, Sterne A, Purcell S, Cherny S, Webster M, Rijsdijk F, Asherson P, Ball D, Craig I, Eley T, et al.: GENESiS: creating a composite index of the vulnerability to anxiety and depression in a community-based sample of siblings. Twin Res 2000, 3:316-322.

25. Schmitz N, Hartkamp N, Kiuse J, Franke GH, Reister G, Tress W: The Symptom Check-List-90-R (SCL-90-R): a German validation study. Qual Life Res 2000, 9:185-193. 
26. Schmitz N, Kruse J, Tress W: Psychometric properties of the General Health Questionnaire (GHQ-12) in a German primary care sample. Acta Psychiatr Scand 1999, 100:462-468.

27. Thompson B: Exploratory and Confirmatory Factor Analysis: Understanding Concepts and Applications Washington DC, Amer Psychological Assn; 2004.

28. Graetz B: Multidimensional properties of the General Health Questionnaire. Soc Psychiatry Psychiatr Epidemiol I991, 26:132-138.

29. Cronbach L: Coefficient Alpha and the internal structure of tests. Psychometrika 1951, 16:297-334.

30. Arbuckle J: Amos 3.6. In Easy Structural Equation Modeling and Confirmatory Factor Analysis Mahwah, Lawrence Erlbaum Assoc Inc; 1996.

31. Muthen B: A general structural equation model, with dichotomous, ordered categorical and continuous latent variable indicators. Psychometrika 1984, 49: I I5-132.

32. Christoffersen A: Factor analysis of dichotomized variables. Psychometrika 1975, 40:5-22.

33. Browne M, Mels G: RAMONA User's Guide Columbus, The Ohio State University; 1992.

34. Weisaeth L: A study of behavioural responses to an industrial disaster. Acta Psychiatr Scand Suppl 1989, 355:13-24.

35. Haarmann H, Ashling G, Davelaar E, Usher M: Age-related declines in context maintenance and semantic short-term memory. QJ Exp Psychol A 2005, 58:34-53.

36. Lorsbach T, Simpson G: Age differences in the rate of processing in short-term memory. J Gerontol I984, 39:3 I5-32I.

37. Maylor E, Vousden J, Brown G: Adult age differences in shortterm memory for serial order: data and a model. Psychol Aging 1999, 14:572-594.

\section{Pre-publication history}

The pre-publication history for this paper can be accessed here:

http://www.biomedcentral.com/1471-2458/6/230/pre

pub

Publish with Biomed Central and every scientist can read your work free of charge

"BioMed Central will be the most significant development for disseminating the results of biomedical research in our lifetime. "

Sir Paul Nurse, Cancer Research UK

Your research papers will be:

- available free of charge to the entire biomedical community

- peer reviewed and published immediately upon acceptance

- cited in PubMed and archived on PubMed Central

- yours - you keep the copyright

Submit your manuscript here:

http://www.biomedcentral.com/info/publishing_adv.asp 